\title{
Productivity Improvement in the Pride's Spare Parts Manufacturing using Computer Simulation and Data Envelopment Analysis
}

\author{
Bahareh Vaisi \\ Ph.D. Candidate \\ School of Industrial Engineering, South Tehran \\ Branch, Islamic Azad University, Tehran, Iran
}

\author{
Sadigh Raissi \\ Associate Professor \\ School of Industrial Engineering, South Tehran \\ Branch, Islamic Azad University, Tehran, Iran
}

\begin{abstract}
Generally, improving production rate is a typical crucial problem in any manufacturing system. To cope with the problem, different kinds of scientific method stems from trial and error may be applied which imposes high costs. Rottenly testing any proposed scenarios may have significant effect on both operational management and manufacturing cost. This paper considers a simulation based data envelopment analysis (DEA) applied into a well-known automobile spare part manufacturer in Iran to improve production rate. The purpose is to select the optimum scenario, which could maximize the system efficiency. The techniques of Monte Carlo simulation and linear programming adopted to solve the problem. In order to make the frame efficient, the DEA model improved according to the features of the system simulation. Applying this method could conduct us to gain more than $1 \%$ improvement in production rate using the existing resources.
\end{abstract}

\section{Keywords}

Computer Simulation, Production rate, Design of experiments, Data Envelopment Analysis.

\section{INTRODUCTION}

It is noteworthy to study the atmosphere of a manufacturing system and to anticipate how the system will operate under different production experiments. Production process modeling and simulation are useful techniques to support manufacturing systems and to help in management decision making. Production rate is a general problem which manufacturing systems are involved with. Therefore, designing various scenarios they try to operate them by trial and error in order to find the best scenario which leads to higher and more efficient production.

Stochastic discrete event system simulation is an appropriate efficient modeling tool to analyze complex systems due to its allowances to accurately describe a system by logically complex and often non-algebraic variables and constraints accurately. Using simulation as a tool for enriching existing manufacturing systems might be significant because it allows assessing the effect of alterations on the performance of the overall system.

The Oxford English dictionary describes simulation as: "the technique of imitating the behavior of some situation or system (economic, mechanical, etc.) by means of an analogous model, situation, or apparatus, either to gain information more conveniently or to train personnel". In simulation, a computer is used because of its speed in mimicking a system over a period. Again, most of these simulations could (in theory at least) be performed without a computer. Nevertheless, in most organizations, important problems have to be solved quickly. Computer simulation methods have developed since the early 1960s and may well be the most commonly used of all the analytical tools of management science [1].

In a study, Maria (1997) answered some critical questions regarding an overview of simulation modeling. The paper includes anyone who is involved in system design and modification such as; system analysts, management personnel, engineers, military planners, economists, banking analysts, and computer scientists. The study may useful for those unfamiliar with the area of discrete event simulation [2].

As simulation is a great tool for assessing systems, so simulation introduction is very useful. Introducing simulation and modeling and the main concepts in simulation is developed in Carson (2003)'s study. In addition, a number of key notes related to simulation team and managing a simulation project presented through some guidelines in this study [3].

To predict the behavior of Polymer production process accurately and comprehensively, a study is done by Krallis et al. (2010). The goal of this study is to increase plant efficiency, improve product quality and decrease the impact to environment. Using a series of advanced software packages, a great number of polymerization systems are simulated. Thus, significant benefits achieved on the polymer plant operability [4].

Cimino et al. (2010) fully reviewed commercial discrete event simulation software and its advantages. They surveyed some critical aspects such as domains of application, 3D and virtual reality potentialities, simulation languages and prices are considered. Moreover, a supply chain order performance simulator (SCOPS, developed in $\mathrm{C}++$ ) is presented for investigating the inventory management problem along the supply chain under dissimilar supply chain scenarios [5].

A real time simulation model is developed for a modular housing production system in a study done by Alhaj Ali et al. (2010). They mapped out the activities of a considered system and collected data of approximately 20 cycles for all activities at the assembly and subassembly stations. They observe the animation of the entities at a low speed run then, validate the model by comparing the production model performance measures with the real system outputs. The results show that the system is a bottleneck free system [6].

In order to alleviate the problems facing with garment manufacturing system, which stem from manual-operations oriented system, a study presented by Kitaw et al. (2010). They develop a simulation model which represent real production process scenarios of garment products and helps to identify the bottlenecks and enhance production system performance. Based on the data from real system, they 
considered different alternative systems to find the best one [7].

In order to improve the capacity of a manufacturing facility, a simulation model was created taking into account numerous system constraints and process time logic, by Qayyum and Dalgarno(2012). The results of the model compared then with the results from the real system. They find that, both the real system and the model have sufficient overlap within a 95\% confidence interval to be considered a fair representation of the behavior of the system [8].

Regarding assembly lines in a production process, which supplied from a central logistic center and respecting the dependence of transportation requests on the warehouse picking process, the problem considered as an integrated formulation problem in a study by Vonolfen et al. (2012). Using the transport simulation model, they simulate the internal transport of parts between the warehouse and the individual workstations. They examined their approach in a scenario based on a real world data from Rosenbauer, one of the world's largest suppliers of firefighting vehicles. The results show that, warehouse optimizing leads to an efficient transportation in an integrated formulation problem [9].

A solution for developing production strategies using simulation model analysis is presented by Serban and Calin (2012). Their analysis includes the structural model, the statistic model and the behavioral model. They proposed to use one of the presented model or a combination between three possibilities based on simulation analysis to develop an efficient production strategy [10].

Considering the incremental sheet forming (ISF), Lora et al. (2013) evaluate computer simulation with real experiments. ISF is a process to produce the small batches of parts, rapid prototyping, and manufacturing flexibility with reduced operational cost. The results were consistent with the experimental manufacture of a symmetrical sample [11].

This paper is presented as follows: in section 2 the system conceptual model presented and the seven performance measures used for fully system analysis. Section 3 shows computer simulation model of existing system applying the Enterprise Dynamics ${ }^{\mathrm{TM}}$ computer simulation package. In section 4 results and discussion are shown. Finally conclusions presented in section 5 .

\section{CONCEPTUAL MODEL}

In this study, a case study in Pride's spare parts manufacturing industry in Kurdistan presented which produces trunk jack with the physical characteristics of 16 millimeters pipe link to 8 millimeters shaft, how the behavior of a part of system during the time of analysis is captured in a critical path chart and depicted in Figure 1.

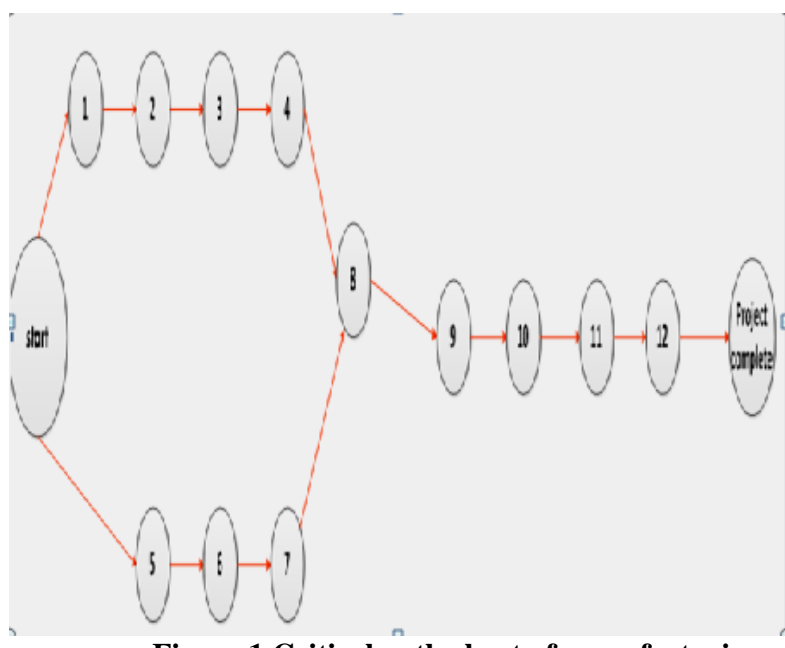

Figure 1.Critical path chart of manufacturing process in Gordon Pride's trunk jack factory

In the Figure 'circle' symbol shows as activities, this chart is drawn and description of each system's activity, based on the figure, is indicated in Table 1.

Table1. Activities in Gordon Pride's trunk jack manufacturing system

\begin{tabular}{|c|c|}
\hline Operations & \multicolumn{1}{|c|}{ Symbol } \\
\hline 1 & Cutting pipe \\
\hline 2 & Drill \\
\hline 3 & Argon welding \\
\hline 4 & Press welding \\
\hline 5 & Threaded shaft \\
\hline 6 & Shaft polishing \\
\hline 7 & Shaft assemble \& rivet \\
\hline 8 & Assembling shaft \& pipe \\
\hline 9 & Ring \\
\hline 10 & Pneumatic press \\
\hline 11 & Nitrogen charging \\
\hline 12 & Washing \\
\hline
\end{tabular}

For evaluating performance of the system (our case study), some performance measures (PFMs) defined as output variables. These variables defined as the outputs of computer simulation model. Table 2 shows such PFMs in the present manufacturing system.

Table2. Performance Measures of Gordon Pride's trunk jack manufacturing system (Times in seconds)

\begin{tabular}{|c|c|}
\hline PFMs & Description \\
\hline$Y_{1}$ & Average stay assemble \\
\hline$Y_{2}$ & Max output assemble \\
\hline$Y_{3}$ & Max output cutting pipe \\
\hline$Y_{4}$ & Average output queue number 10(Q10) \\
\hline$Y_{5}$ & Average stay Q15 \\
\hline$Y_{6}$ & Average stay Q4 \\
\hline$Y_{7}$ & Average output per a day( in 8 hours) \\
\hline
\end{tabular}

\section{COMPUTER SIMULATION MODEL}

To illustrate this process, the Enterprise Dynamics (ED) as a computer simulation tool is used to analyze the system under different scenarios. Figure 2 depicted the conceptual model of the system using the ED routines [12]. 


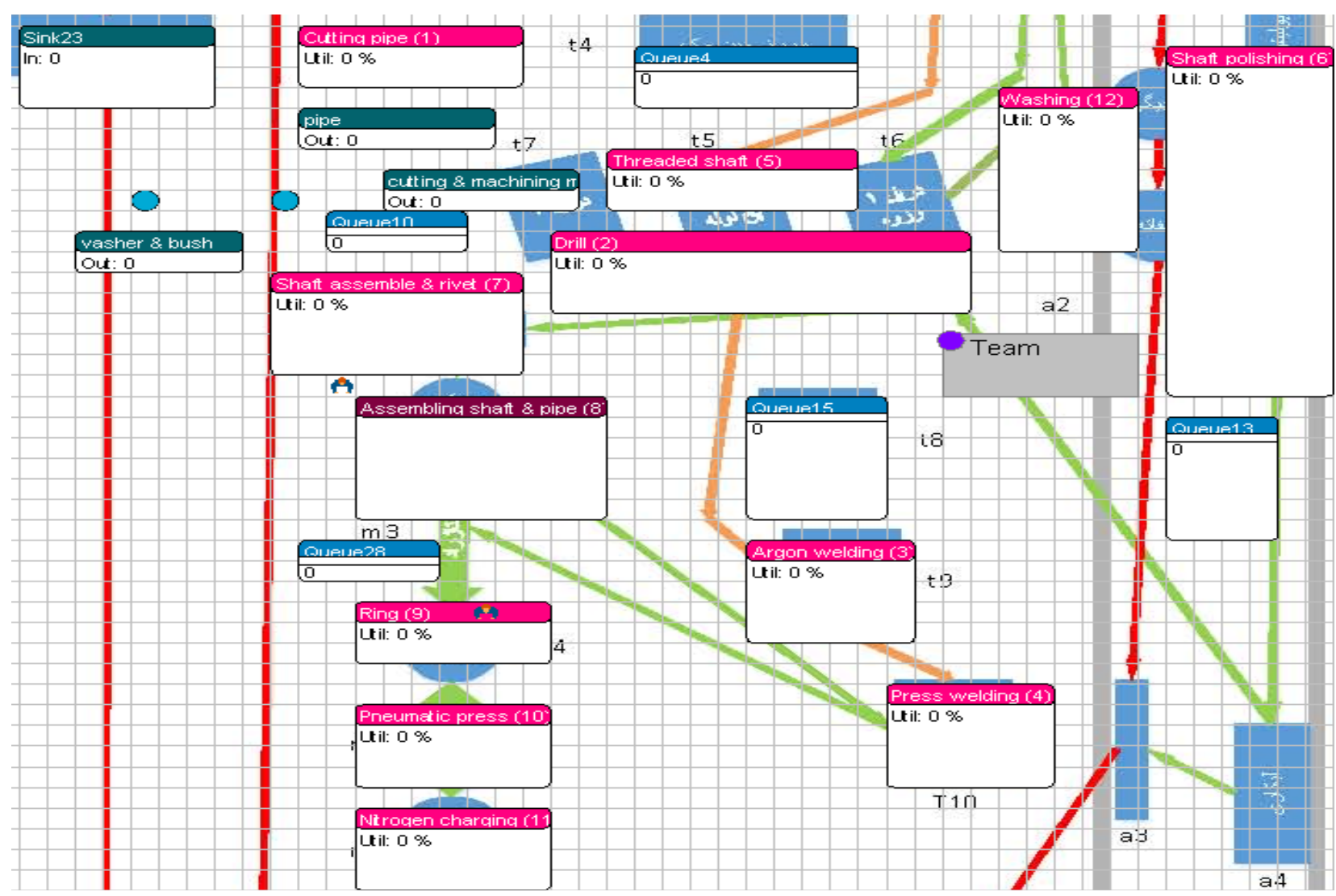

Figure2. The snap shot of created simulating model using ED software

For modeling the entrance process of Pipe and Rebar, two Source atoms were used which is shown in Figure 2 as Pipe and Cutting \& Machining Rebar (CMR). Server atom is used to model the mentioned operations related to the Critical path chart of manufacturing process (see Figure 1). Work in process and storage areas for work items are indicated as Queue atom like Queue 4. Assembler atom is used in ED model to show merging of Pipe and Shaft, which are from several sources.

In order to fully customizing the system in ED, some special 4DScript codes are used to run the simulated current state model accurately. There are some extra operators in the factory, whom are used in some situations. So a Team consists of 2 operators is defined and allocated the operators to the required operations. Then, using 4dscript coding in the required atoms, these commands in the following Servers, namely shaft assemble and rivet (operation 7) and ring (operation9) is fixed (see table 1):

Server: Trigger on entry=

calloperators(AtomByName([Team],model),1)

Trigger on exit $=$

FreeOperators(AtomByName([Team],Model),i).
Another 4dscript coding is used for Assembler (for modeling the assembling process of shaft and pipe), here the following codes are used:

\section{Assembler: Trigger on entry= calloperators(AtomByName([Team],model),1) \\ Trigger on exit $=$ FreeOperators(AtomByName([Team],Model),i).}

To properly illustrate this process, information and data for a period of six months are gathered. Applying MINITAB $^{\mathrm{TM}}$ statistical package allow us to fit some theoretical distribution to the data samples. The histogram for such data samples leads us for alternative distributions. As shown in histogram, it appears that the Weibull, Normal and Gamma distribution might be viable candidates for the best fits to inter-arrival process and cycle times (CTs). As a sample, the result of fitting a Weibull distribution to the data derived from cutting pipe Cycle time, is shown in Figure 3. 


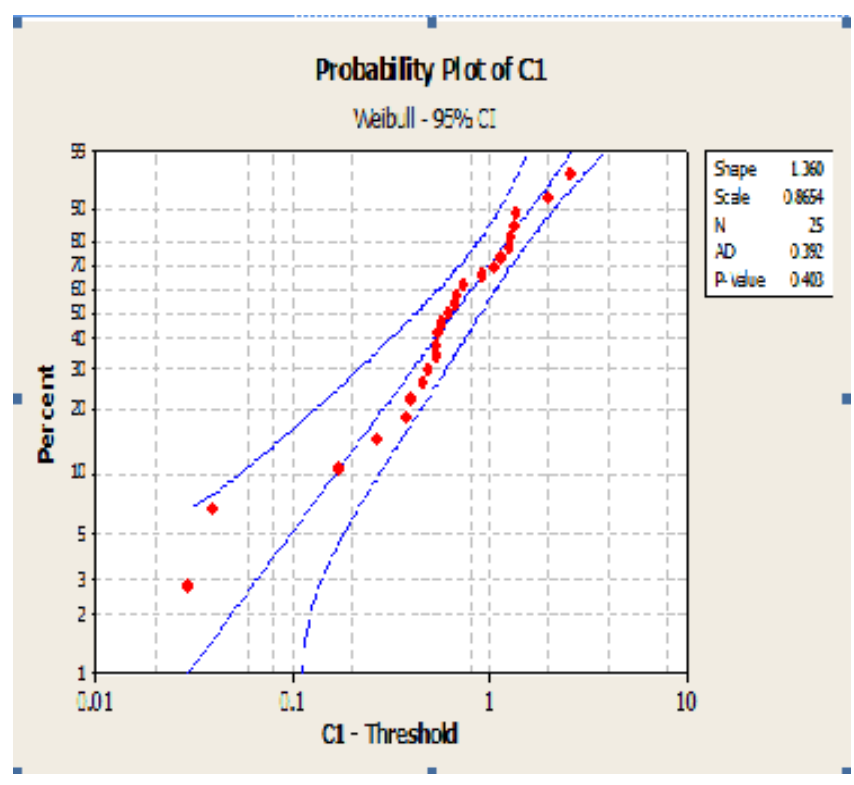

Figure3. Fitting a Weibull distribution to the data derived from cutting pipe Cycle time

The report that accompanies this figure indicates that Weibull $(1.36,0.8654)$ could model such activity well. Here distribution parameters depicted in the couples are $\alpha=1.36$ and $\beta=0.8654$ respectively. For such distribution, the p-value of $(0.403)$ is not statistically significant. The goodness of fit hypothesis indicates that the Weibull distribution remains a strong candidate for representing the data sample. Table 3 delivers information of the best fits for all stochastic variables.
Table3. Statistical characteristics of required Atoms in Gordon Pride's trunk jack manufacturing system

\begin{tabular}{|c|c|c|c|}
\hline Input var. & Var. code & Stat. dist. & Parameters \\
\hline $\begin{array}{c}\text { CT of } \\
\text { Cutting pipe }\end{array}$ & CT1 & Weibull & $\begin{array}{c}\alpha=1.36 \\
\beta=0.8654\end{array}$ \\
\hline CT of Drill & CT2 & Normal & $\begin{array}{c}\mu=11.15 \\
\text { StDev=1.047 }\end{array}$ \\
\hline $\begin{array}{l}\text { CT of Argon } \\
\text { welding }\end{array}$ & CT3 & Normal & $\begin{array}{c}\mu=12.64 \\
\text { StDev }=1.379\end{array}$ \\
\hline $\begin{array}{l}\text { CT of Press } \\
\text { welding }\end{array}$ & CT4 & Gamma & $\begin{array}{c}\alpha=83.47 \\
\beta=0.03027\end{array}$ \\
\hline $\begin{array}{c}\text { Inter-arrival } \\
\text { time of CMR }\end{array}$ & & Normal & $\begin{array}{c}\mu=19.5 \\
\text { StDev }=0.9978\end{array}$ \\
\hline $\begin{array}{l}\text { Time till first } \\
\text { product of } \\
\text { CMR }\end{array}$ & & Normal & $\begin{array}{c}\mu=19.5 \\
\text { StDev }=0.9978\end{array}$ \\
\hline $\begin{array}{c}\text { CT of } \\
\text { Threaded } \\
\text { shaft }\end{array}$ & CT5 & Normal & $\begin{array}{c}\mu=5.322 \\
\text { StDev }=0.5909\end{array}$ \\
\hline $\begin{array}{l}\text { CT of Shaft } \\
\text { polishing }\end{array}$ & CT6 & Normal & $\begin{array}{c}\mu=3.046 \\
\text { StDev }=0.4116\end{array}$ \\
\hline $\begin{array}{l}\text { CT of Shaft } \\
\text { assemble \& } \\
\text { rivet }\end{array}$ & CT7 & Normal & $\begin{array}{c}\mu=8.644 \\
\text { StDev }=0.6\end{array}$ \\
\hline $\begin{array}{c}\text { CT of } \\
\text { Assembling } \\
\text { shaft \& pipe }\end{array}$ & CT8 & Normal & $\begin{array}{c}\mu=1.9 \\
\text { StDev }=0.12\end{array}$ \\
\hline CT of Ring & CT9 & Normal & $\begin{array}{c}\mu=2.759 \\
\text { StDev }=0.1596\end{array}$ \\
\hline $\begin{array}{c}\text { CT of } \\
\text { Pneumatic } \\
\text { press }\end{array}$ & CT10 & Normal & $\begin{array}{c}\mu=5.227 \\
\text { StDev }=0.3667\end{array}$ \\
\hline $\begin{array}{l}\text { CT of } \\
\text { Nitrogen } \\
\text { charging }\end{array}$ & CT11 & Normal & $\begin{array}{c}\mu=20.06 \\
\text { StDev }=0.6103\end{array}$ \\
\hline $\begin{array}{c}\text { CT of } \\
\text { Washing }\end{array}$ & CT12 & Uniform & $\begin{array}{c}a=0 \\
b=1500\end{array}$ \\
\hline
\end{tabular}

$\alpha=$ Shape, $\beta=$ Scale, $\mu=$ Mean, StDev $=$ Standard

Deviation, $a=$ minimum value, $b=$ maximum value

Then the requisite simulation adjustments for running the model in ED are made.

\section{RESULTS AND DISCUSSION}

\subsection{Applying Simulation of existing System}

To express the performance of the proposed simulated model, these settings were done in the experimentation menu. In the experiment wizard the amounts of observation, number of observations and warm up period set on 80,30 and 8 hours respectively. Table 4 shows the PFMs of real system.

Table4. The performance measures of real system (current state)

\begin{tabular}{|c|c|}
\hline$Y_{1}$ & 7.65 \\
\hline$Y_{2}$ & 4274 \\
\hline$Y_{3}$ & 2879 \\
\hline$Y_{4}$ & 1477.07 \\
\hline$Y_{5}$ & 97486.49 \\
\hline$Y_{6}$ & 9546.27 \\
\hline$Y_{7}$ & 946 \\
\hline
\end{tabular}


Afterwards, some accepted real results used for validating the simulation model. In the real system, the output of Cutting pipe is almost twice over the arrival of rebar to Threaded shaft. It is clear that, there may be some imbalances in Assembling shaft \& pipe, as it this operation requires pipe and shaft (the output of operation 4 and the output of operation 7) to be completed. Therefore, the stay time of Cutting pipe's output in the system will increase. Furthermore, two operators are assigned to the operations 7,8 and 9 (see Table 1) whenever that is necessary. Allocating the above number of operators in this way or even existence of them in the system is considerable and should be discussed.

All of the above arguments may affect the production rate of factory and this is also an important factor which decreases productivity in the system.

\subsection{The Validity of Simulation Model}

Face validation is mainly concerned with making sure our robust model provides useful results by being a close enough approximation to the real system. Here this form of analysis is done by performing a two sample nonparametric MannWhitney statistical hypothesis testing on the difference between the mean of the selected output of the computer simulation model (PFM) and the same data gathered from the real system. Based upon a 25 sample applied in the Minitab $^{\mathrm{TM}}$, p-value of 0.0786 for the Mann-Whitney statistics reject any evidence in mean differences at $10 \%$ significance level, consequently the ED model is ready to answer the question for which it was created to answer.

\subsection{Design of Experiments}

Design of experiment (DOE) method is used for designing scenarios and the methodology of full factorial DOE is applied. DOE is a method to identify the important factors in a process then identify and fix the problem in a process. In real engineering settings, there are usually multiple factors involved and it is typically important to consider them together in case they interact. Hence factorial design is a method to determine the effects of multiple variables on a response. This method reduces the number of experiments one has to perform by studying multiple factors simultaneously. Because factorial design can lead to a large number of trials, which can become expensive and time-consuming, factorial design is best used for a small number of variables with few states (1 to 3 ). Factorial design works well when interactions between variables are strong and important and where every variable contributes significantly.

Here, input variables called as $\mathrm{X}_{1}, \mathrm{X}_{2}$ and $\mathrm{X}_{3}$ for number of operators in a team, mean parameter of rebar's arrival rate and breakdowns of cutting pipe operation respectively.

The following codes are defined on DOE to increase productivity, efficiency and reduce waiting time in the system. Table 5 presents the ranges of settings.
Table5. Codification parameter setting

\begin{tabular}{|c|c|c|}
\hline $\begin{array}{c}\text { Input variables } \\
(\mathbf{X})\end{array}$ & $\begin{array}{c}\text { Low } \\
(-\mathbf{1})\end{array}$ & $\begin{array}{c}\text { High } \\
(\mathbf{+ 1})\end{array}$ \\
\hline $\mathrm{X}_{1}$ & 0 & 5 \\
\hline $\mathrm{X}_{2}$ & 9 & 19.5 \\
\hline $\mathrm{X}_{3}$ & 0 & $\mathrm{Hr}(6.5)$ \\
\hline
\end{tabular}

Then, based on Table 5 and full factorial DOE method, the scenarios created. Table 6 indicates the results of simulation runs under different scenarios.

In order to compare the true efficiency of the scenarios, data envelopment analysis (DEA) applied on simulation results. For years, data envelopment analysis (DEA) has been considered as one of the most well-known methods for measuring the relative efficiency of similar units. DEA technique has different advantages such as considering various inputs and outputs. DEA is a mathematical method of performance assessment of homogeneous decision making units (DMUs). DEA has been successfully implemented to evaluate different kinds of DMUs such as producer units, in recent years.

Each scenario as a DMU is considered, since their inputs and outputs are the same type. Then applying the model first developed by Charnes, Cooper and Rhodes called as CCR model the efficiency of each scenario is calculated [13].

They formulated their efficiency model for ' $n$ ' unit decision maker with ' $m$ ' input and 's' output as a ratio of a weighted sum of outputs to a weighted sum of inputs. The efficiency of unit 'zero' is a fractional linear program as shown in (1).

Where ' $u_{r}$ ', and ' $v_{i}$ ' are the weight to be applied to the outputs and inputs. Based on computations by Lingo the results are shown in Table 7 [14], [15].

$$
\begin{aligned}
& \max E_{o}=\frac{\sum_{r=1}^{\mathrm{S}} u_{r} y_{r 0}}{\sum_{i=1}^{m} v_{i} x_{i 0}} \\
& \text { s.t. } \frac{\sum_{r=1}^{S} u_{r} y_{r j}}{\sum_{i=1}^{m} v_{i} x_{i j}} \\
& u_{r} \geq 0 \\
& r=1,2, \ldots \ldots . s \\
& v_{i} \geq 0 \\
& j=1,2, \ldots \ldots, n \\
& \mathrm{i}=1,2, \ldots \ldots . \mathrm{m}
\end{aligned}
$$


Table6. The scenario design based on coded ranges

\begin{tabular}{|c|c|c|c|c|c|c|c|c|c|c|}
\hline Scenario\# & $\mathrm{X}_{1}$ & $\mathrm{X}_{2}$ & $\mathrm{X}_{3}$ & $\mathrm{Y}_{1}$ & $\mathrm{Y}_{2}$ & $\mathrm{Y}_{3}$ & $\mathrm{Y}_{4}$ & $\mathrm{Y}_{5}$ & $\mathrm{Y}_{6}$ & $\mathrm{Y}_{7}$ \\
\hline $\mathbf{1}$ & +1 & +1 & +1 & 7.65 & 4277 & 2338 & 1476.6 & 94464.36 & 8879.03 & 958.5 \\
\hline $\mathbf{2}$ & -1 & +1 & +1 & 7.68 & 4320 & 2339 & 1476.97 & 104448.2 & 8801.13 & 949 \\
\hline $\mathbf{3}$ & +1 & -1 & +1 & 7.65 & 4276 & 2339 & 1685.07 & 103176.6 & 8914.13 & 927 \\
\hline $\mathbf{4}$ & +1 & +1 & -1 & 7.65 & 4276 & 2880 & 1477 & 93058.12 & 9546.6 & 932 \\
\hline $\mathbf{5}$ & -1 & -1 & +1 & 7.68 & 4320 & 2339 & 1908.27 & 174365.5 & 8964.2 & 961 \\
\hline $\mathbf{6}$ & -1 & +1 & -1 & 7.67 & 4320 & 2879 & 1476.93 & 95245.97 & 9532.5 & 950 \\
\hline $\mathbf{7}$ & +1 & -1 & -1 & 7.65 & 4275 & 2880 & 1683.9 & 110027.8 & 9549.13 & 938 \\
\hline $\mathbf{8}$ & -1 & -1 & -1 & 7.67 & 4320 & 2880 & 1904.03 & 174770.3 & 9529.33 & 957 \\
\hline
\end{tabular}

Table7. The performance measurement of scenarios based on DEA

\begin{tabular}{|c|c|}
\hline Scenario \# & Efficiency \\
\hline Current state & 0.461 \\
1 & 0.456 \\
2 & 0.461 \\
3 & 0.996 \\
4 & 0.461 \\
5 & 1 \\
6 & 0.461 \\
7 & 1 \\
8 & 1 \\
\hline
\end{tabular}

It is clear that, higher efficiency indicates better scenarios. Therefore, scenarios with numbers ' 5 ', ' 7 ' and then 8 respectively will be helpful in order to improve the situation of this system. DMUs with efficiency value equals to ' 1 ' are defined as efficient DMUs (scenarios). Then, Cross efficiency model is used to improve the discrimination power of proposed DEA model and separation of efficient scenarios (efficient DMUs); according to the results of Table 8 , by setting all of input variables ( $\mathrm{X}$ values) in minimum value, the superior DMU (scenario) is selected which is DMU 8 .

Table8. The cross efficiency matrix of efficient scenarios

\begin{tabular}{|c|c|c|c|}
\hline DMU\# & $\mathbf{5}$ & $\mathbf{7}$ & $\mathbf{8}$ \\
\hline $\mathbf{5}$ & $\mathrm{e}_{55}=1$ & $\mathrm{e}_{57}=0.977$ & $\mathrm{e}_{58}=0.999$ \\
\hline $\mathbf{7}$ & $\mathrm{e}_{75}=0.941$ & $\mathrm{e}_{77}=1$ & $\mathrm{e}_{78}=1$ \\
\hline $\mathbf{8}$ & $\mathrm{e}_{85}=0.997$ & $\mathrm{e}_{87}=0.631$ & $\mathrm{e}_{88}=1$ \\
\hline $\mathbf{e}_{\mathbf{k}}$ & 0.969 & 0.804 & 0.999 \\
\hline
\end{tabular}

To enhance the PFMs, according to the experts, the $(8,9,10)$ range for ' $\mathrm{X}_{2}$ ' is tested and run in $\mathrm{ED}$. The results are observed in Table 9.

It can be inferred from the results that, scenario ' $\mathrm{C}$ ' considering higher production rate-which is the company's main goal- with $1 \%$ increase per 8 hours, has a better situation compared to the previous scenario number ' 8 '.

\section{CONCLUSION}

In this study, in order to improve the production rate of a manufacturing facility, a simulation model was created, taking into account numerous system constraints and process time logic based on statistical methods. This model was validated against production rate and work center utilizations within a 95\% confidence interval.

Applying ED, the simulated model can allow various modeling scenarios to be examined in future simulations with less expense, time and resources than experimentation with the real world system. The results then analyzed and used to inform changes in manufacturing processes, system constraints and capital expenditure, in order to improve the production rate of the factory.

As it shown from the results;

- Scenarios with numbers ' 5 ', '7', ' 8 ' and then 3 respectively are operational scenarios based on DEA model, in order to improve the situation of system using the existing resources.

- applying cross efficiency model on efficient scenarios, scenario ' 8 ' is considered as a superior scenario; therefore, based on this scenario if $\mu$ parameter of CMR's inter arrival time is given 10 seconds, Average output per a day (in 8 hours) and Average stay Q4 will increase; while Max output cutting pipe, Average output Q10 and Average stay Q15 will diminish. In this case, Average stay of assemble and Max output assemble remains permanent.

Based on this two-level decision making, scenario ' $\mathrm{C}$ ' (transformed scenario of ' 8 ') shows almost $0.3 \%$ increasing in production rate compared to the scenario ' 8 ' whereas $1.5 \%$ is the increasing rate of production in comparison with the real system.

This study can be extended for future works in different ways,

- The scenarios will be more complete by extending the defined ranges in DOE.

-The proposed scenarios were focused basically on improving the production rate of the manufacturing system, while there are other important factors that can be considered such as minimizing waiting time (average stay) and etc. 
Table9. The scenario design for ' $\mathrm{X}_{2}$ ' based on the experts

\begin{tabular}{|l|l|l|l|l|l|l|l|l|l|l|}
\hline & \multicolumn{1}{|c|}{$\mathbf{X}_{\mathbf{1}}$} & \multicolumn{1}{|c|}{$\mathbf{X}_{\mathbf{2}}$} & \multicolumn{1}{|c|}{$\mathbf{X}_{\mathbf{3}}$} & $\mathbf{Y}_{\mathbf{1}}$ & $\mathbf{Y}_{\mathbf{2}}$ & $\mathbf{Y}_{\mathbf{3}}$ & $\mathbf{Y}_{\mathbf{4}}$ & $\mathbf{Y}_{\mathbf{5}}$ & $\mathbf{Y}_{\mathbf{6}}$ & $\mathbf{Y}_{\mathbf{7}}$ \\
\hline $\mathbf{A}$ & $\mathbf{0}$ & $\mathbf{8}$ & $\mathbf{0}$ & 7.68 & 4320 & 2879 & 1910.27 & 175442.1 & 9542.3 & 934 \\
\hline B & $\mathbf{0}$ & $\mathbf{9}$ & $\mathbf{0}$ & 7.67 & 4320 & 2880 & 1904.03 & 174770.3 & 9529.33 & 957 \\
\hline $\mathbf{C}$ & $\mathbf{0}$ & $\mathbf{1 0}$ & $\mathbf{0}$ & 7.68 & 4320 & 2879 & 1902.37 & 171329.6 & 9546.1 & 960 \\
\hline
\end{tabular}

\section{REFERENCES}

[1] Pidd, M. Computer Simulation in Management Science. 1986. Reprinted with corrections, Wiley.

[2] Maria, A. 1997. Introduction to modeling and simulation. In Proceedings of the 1997 Winter Simulation Conference, edited by . S. Andradóttir, K. J. Healy, D. H. Withers, and B. L. Nelson.

[3] Carson, J. S. 2003. Introduction to modeling and simulation. In Proceedings of the 2003 Winter Simulation Conference, S. Chick, P. J. Sánchez, D. Ferrin, and D. J. Morrice, eds., Piscataway, New Jersey:Institute of Electrical and Electronics Engineers.

[4] Krallis, A., Pladis, P., Kanellopoulos, V., Saliakas, V., Touloupides V., and Kiparissides, C. 2010. Design, Simulation and optimization of polymerization processes using advanced open architecture software tools. 20th European Symposium on Computer Aided Process Engineering - ESCAPE20 S. Pierucci and G. Buzzi Ferraris (Editors)@ 2010 Elsevier B.V.

[5] Cimino, A., Longo F., and Mirabelli, G. "A General simulation framework for supply chain modeling: State of the Art and Case Study", IJCSI International Journal of Computer Science Issues, March 2010, 7(3), www.IJCSI.org.

[6] Alhaj Ali, S., Abu Hammad, A., Hastak, M., and Syal, M. "Analysis of a Modular Housing Production System Using Simulation", Jordan Journal of Mechanical and Industrial Engineering, 2010, 4(2), 256 - 269.

[7] Kitaw, D., Matebu, A., and Tadesse, S. "Assembly line balancing using simulation technique in a garment manufacturing firm", Journal of EEA, 2010, 27.

[8] Qayyum, A., and Dalgarno, K. 2012. Improving manufacturing systems through use of simulation. Technical report. School of Mechanical and Systems Engineering, Newcastle University, Newcastle.

[9] Vonolfen, S., Kofler, M., Beham A., and Affenzeller, M. 2012. Optimizing assembly line supply by integrating warehouse picking and forklift routing using simulation. In Proceedings of the 2012 Winter Simulation Conference, edited by C. Laroque, J. Himmelspach, R. Pasupathy, O. Rose, and A. M. Uhrmacher.
[10] Serban, R., and Calin, O. 2012.Developing production strategies using simulation model analysis. Annals of DAAAM for 2012 \& Proceedings of the 23rd International DAAAM Symposium, 23(1), Published by DAAAM International, Vienna, Austria, EU.

[11] Lora, F., Boff, U., Yurgel, C. C., Folle, L., and Schaeffer, L. "Validation of the computer simulation process applied to the incremental forming process for the evaluation of strain paths". Key Engineering MaterialsVols,2013, $2453-2461$

TransTechPublications,Switzerland.

[12] Simulation Software / TUTORIAL ANNEXES. Enterprise Dynamics® Copyright (C) 2009 Incontrol Simulation Software B.V. All rights reserved. Papendorpseweg 77, 3528 BJ Utrecht, The Netherlands. www.IncontrolSim.com.

[13] Charnes, A., Cooper, W.W., \& Rhodes, E. "Measuring the efficiency of decision making units", European Journal of Operational Research, 1978, 2, 429-444.

[14] Vaisi, B. 2009. Achieving common set of weights in data envelopment analysis by using multiple criteria decision making. In Proceeding of the 2th International conference of Iranian Operations Research Society, Babolsar University.

[15] Vaisi, B. 2009. Achieving common set of weights in data envelopment analysis by using multiple criteria decision making. In Proceeding of the 2th International conference of Iranian Operations Research Society, Babolsar University.

[16] Moustafa, B.M., and Boumediene, B. "Simulation and optimization of the performance in Hit Solar Cell". International Journal of Computer Applications, 2013, 80 (13).

[17] Maatoug, A., Belalem, G., and Mostefaoui, K. "Modeling and simulation of energy management system for smart city with the formalism DEVS: Towards reducing the energy consumption". International Journal of Computer Applications, 2014, 90 (18).

[18] Jain, N., and Chaba, Y. "Simulation based performance analysis of zone routing protocol in Manet". International Journal of Computer Applications, 2014, 88(4). 